OPEN ACCESS

Edited by:

Jienan Pan,

Henan Polytechnic University, China

Reviewed by:

Fansheng Huang,

China University of Petroleum,

Huadong, China

Lu Jing,

China university of Ming and technology, Beijing, China

Xiaoming Wang,

China University of Geosciences

Wuhan, China

*Correspondence:

Yarong Wang

1172442071@qq.com

Specialty section:

This article was submitted to

Economic Geology,

a section of the journal

Frontiers in Earth Science

Received: 24 November 2021

Accepted: 27 December 2021

Published: 03 February 2022

Citation:

Li X, Wang Y, Lin W, Ma L, Liu D and

Zhang $Y$ (2022) Tectonic

Characteristics and its Effect on Shale

Gas Preservation Condition in the

Jingmen Region.

Front. Earth Sci. 9:821593.

doi: 10.3389/feart.2021.821593

\section{Tectonic Characteristics and its Effect on Shale Gas Preservation Condition in the Jingmen Region}

\author{
Xiaoming $\mathrm{Li}^{1}$, Yarong Wang ${ }^{1 *}$, Wen $\mathrm{Lin}^{2}$, Lihong Ma ${ }^{1}$, Dexun $\mathrm{Liu}^{2}$ and Yu Zhang ${ }^{1}$ \\ ${ }^{1}$ North China Institute of Science and Technology, Langfang, China, ${ }^{2}$ Department of Shale Gas, Research Institute of Petroleum \\ Exploration and Development, Beijing, China
}

Jingmen block is an essential location for the development and exploration of shale gas. The regional structure, the tectonic characteristics, and their influence on shale gas preservation in the Jingmen block were summarized based on observations from drilled cores, seismic data interpretation, FMl imaging logging results, and other methods of subsequent analysis. The study results show that: 1) the overall structure of the study area is simple. The shale corresponding to the Wufeng and Longmaxi formations of the Upper Ordovician and Lower Silurian periods were subjected to compression deformation in Indosinian and early Yanshanianand, following extension and strike-slip transformation in the late Yanshanian period. Structures, including backthrust, echelon, parallel, inversion structures, and rifts, could also be observed 2) Fractures with different tectonic stages and scales have different effects on the preservation degree of shale gas in the study area, resulting in differences in the nature, scale and zone of influence of faults in different regions and 3) The crack associated with fault structure include interlayer low-angle detachment fracture, conjugate shear fracture, reticular fracture, high-angle shear fracture, high-angle strike-slip shear fracture, and high-angle fracture zone. The location and type of fracture development in different stages vary, which affect the shale gas preservation and migration 4) Based on the influence of structures on shale gas preservation, the study area is divided into four categories viz. two favorable areas and two more favorable areas.

Keywords: jingmen, deep, tectonic characteristics, shale gas, preservation condition

\section{INTRODUCTION}

Southern China is endowed with the vast resource potential of marine shale gas. The development of black shale, a deep-water shelf facies in the western part of the Middle Yangtze region during early Cambrian Qiongzhusi and the Late Ordovician Wufeng to early Silurian Longmaxi periods based on their exploration practices and basic research in the Middle and Lower Paleozoic formations of Hubei. The substantial hydrocarbon source of the marine mud shale in these regions was also reported by several researchers (An et al., 2016; Bo et al., 2018; Deng and He, 2018; Shasha et al., 2018; Xiao-Hong et al., 2018). The shale gas in southern China has distinct characteristics from the shale gas in North America. After the reservoir formation, the shale underwent significant deformation in response to multi-stage tectonism, which was also influenced by the combined effects of Huangling paleo-uplift, Guizhong paleo-uplift, Jiangnan-Xuefeng paleo-uplift, and Dabashan orogenic belt during the Mesozoic and Cenozoic periods (Yuming et al., 2013; 


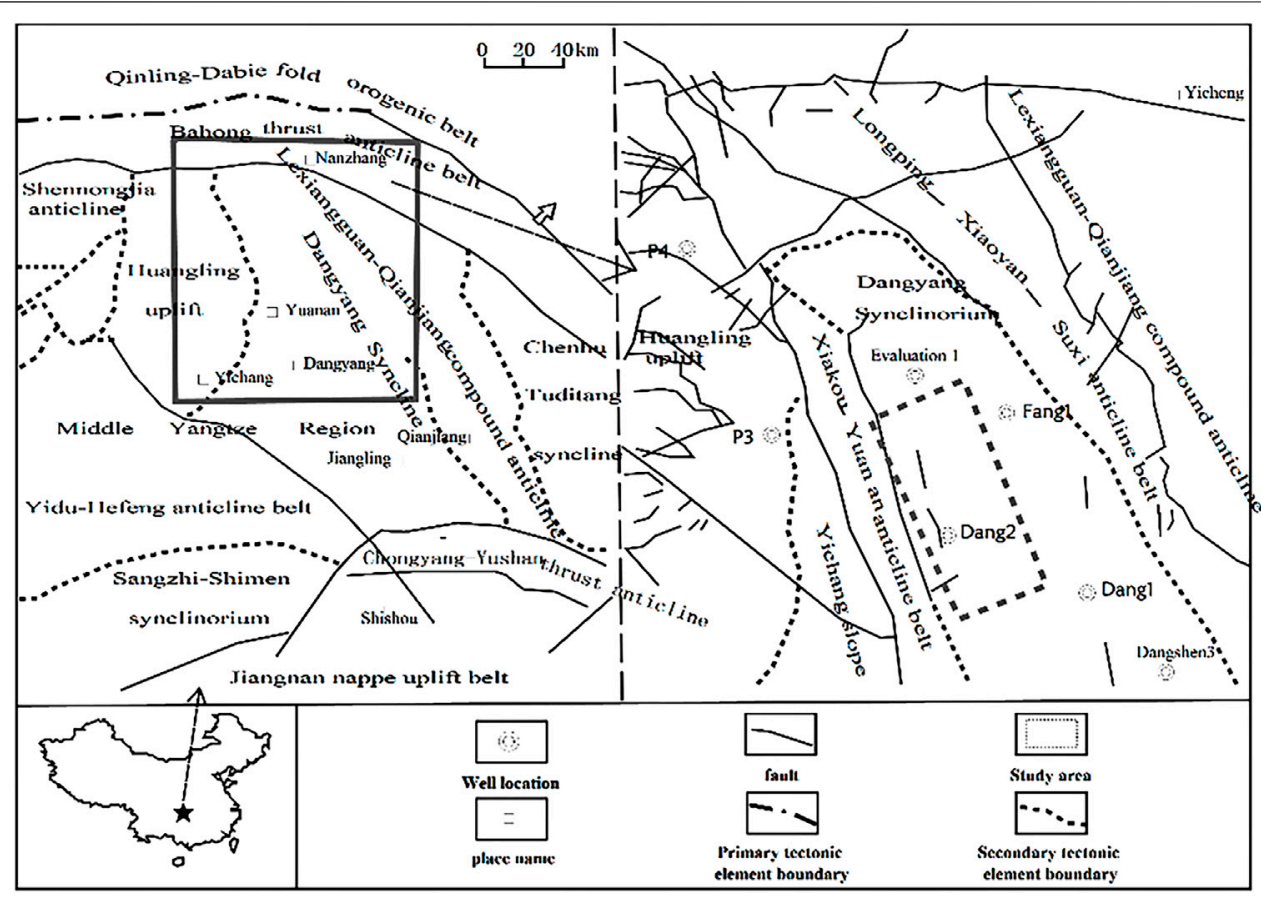

FIGURE 1 | Regional tectonic location in Jingmen area, central Hubei [Revised according to the literature (Chen et al., 2016)].

Kongquan et al., 2020). The subsequent development of intricate faults, folds, strong uplifts, and denudational processes in the western part of the Middle Yangtze block resulted in the rupture of the shale strata and the destruction of the preservation conditions of the original shale gas reservoir (Xusheng, 2014; Zhihong, 2015; Zou et al., 2015; Guo, 2016; Zhai et al., 2017; Xiaoxi et al., 2018). Multiple episodes of complex tectonic movements have occurred in the Jingmen area in Central Hubei. The structural differences among the various phases greatly influence the preservation conditions of shale gas (An et al., 2016; Deng and He, 2018; Guo et al., 2021), resulting in an inconsistency in the enrichment of marine shale gas in the area. The drilling results also confirm the varying productivity and characteristics of gas-bearing blocks.

Several studies have been conducted on the generation conditions, enrichment patterns, and reservoir characteristics of shale gas in Central Hubei (Deng and He, 2018; Shasha et al., 2018; Xiao-Hong et al., 2018). However, research on the influence of the structure of phases on the preservation conditions of shale gas is relatively limited, which restricts the exploration and development of shale gas in Central Hubei. Therefore, establishing the influence of the structure of Jingmen block in central Hubei on the preservation conditions of shale gas is critical for the exploration and subsequent development of well positions. The present study considers the Wufeng -Longmaxi Formation shales from the Jingmen block in central Hubei as the research object to analyze the characteristics of its structural evolution, fracture distribution, scale, and pressure characteristics during formation. In addition, the preservation conditions of shale gas in the study area are also discussed, in conjunction with the gas-bearing characteristics of shale blocks offering a reference for the exploration of shale gas in similar conditions.

The structural characteristics and evolution processes of the area are summarized here, based on the acceptable interpretation of seismic data, FMI imaging logging results, and rock core data analysis. One of the critical elements determining the preservation conditions of shale gas in the area is tectonic activity. The present study investigates the conditions and favorable areas for the preservation of shale gas to guide the prospective exploration and development in the area.

\section{GEOLOGICAL PROFILE}

The Jingmen block is part of the Dangyang synclinorium of the central Hubei fold belt, situated in the middle Yangtze. It is located in the southern Frontier of the Qinling-Dabieshan structural belt on the front margin of the Dahongshan thrustfold belt. It is the front transition zone between the arc-shaped Dabashan and Dahongshan thrust-fold belts (Ma, 2015). It is bordered on the north by the Bahong thrust anticline belt, on the south by Yidu-Hefeng anticline belt, on the west by Huangling uplift, and on the east Lexiangguan-Qianjiang compound anticline (Figure 1).

The study area is characterized by a high slope toward the northwest and a low slope toward the east, developing localized microstructures including several folds and fissures. The neritic carbonate and clastic rock have been developed from bottom to top during the Sinian to Lower Triassic period, with Triassic 


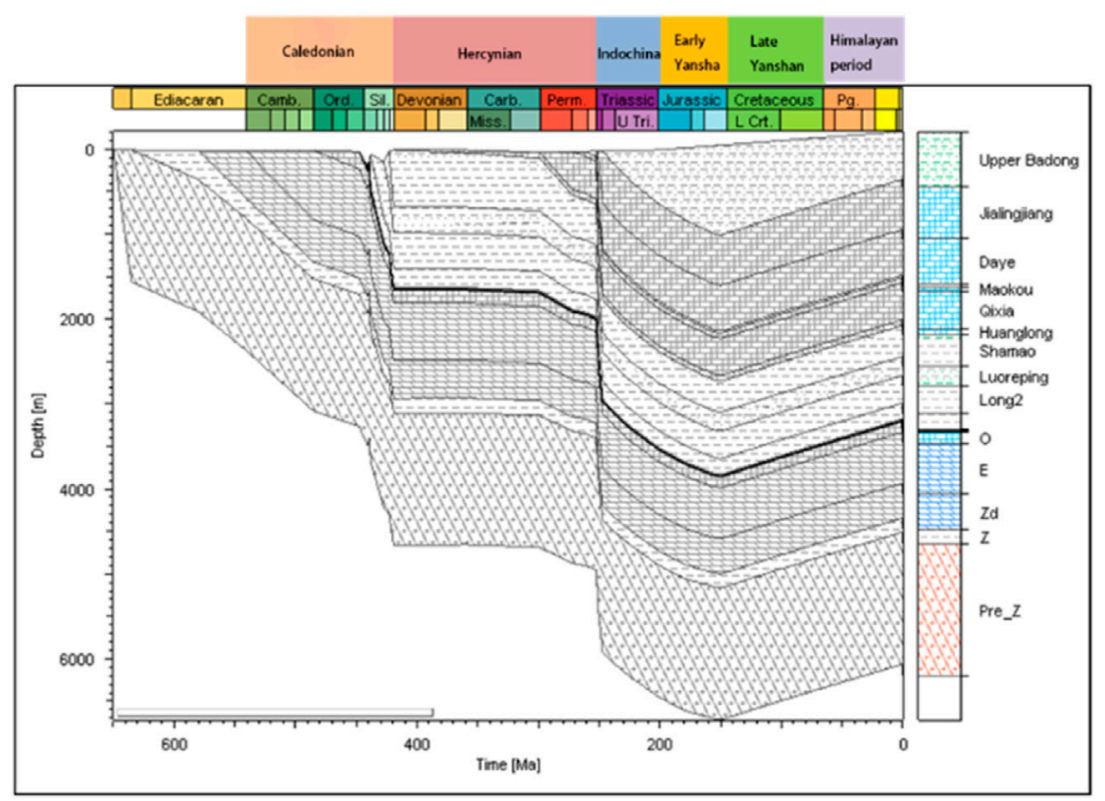

FIGURE 2 | Settlement and burial history map of Wufeng Formation-Longmaxi Formation in Well Yitan 1.

formations exposed on the surface. The Wufeng Formation and the Longmaxi Formation have developed black graptolite-bearing carbonaceous mud shale, a set of deep-water shelf facies, during the Upper Ordovician and Lower Silurian periods, respectively which is a promising period for the development of shale gas. After being subjected to extensive tectonic movement after the formation of the Indosinian, early Yanshan, and late Yanshan and basins (Ma, 2015; Chen et al., 2016; Deng and He, 2018), the tectonic activity of the block has tended to stabilize, with the subsequent weakening of the degree of the stratum deformation. This is favorable for forming a favorable shale gas zone through the enrichment and storage of oil and gas within the Wufeng and Longmaxi Formations.

\section{STRUCTURE AND EVOLUTION OF STUDY AREA WITH FEATURES OF TECTONIC FRACTURE DEVELOPMENT}

The shale strata of Wufeng and Longmaxi Formations of the Upper Ordovician and Silurian periods in the study area has tectonically evolved through three phases with substantial tectonic destruction after deposition. It was formerly believed that shale strata with considerable sedimentary thickness might act as its caprock, but the subsequent tectonic movement does not affect it. This comprehension has several limitations. During the development of Early Paleozoic strata, multiple periods of intense tectonic movement probably affected the sealing conditions to allow the shale gas to escape. The structural variations caused by stratigraphic uplift and fracturing developed during different periods profoundly influenced the shale gas preservation conditions in the area.

\subsection{Tectonic-Burial History}

The sedimentation and burial history of Well Yitan-1 are investigated using the geological background and stratigraphic analysis (Figure 2). The area is reported to have undergone an "early subsidence and late uplift", maintaining periodic deposition before the Indosinian with alternate rapid and slow episodes.

The deposition of the main strata, the marine carbonate rocks of over 5,000 m thickness, was mainly caused by subsidence for a more extended period. The two burial processes of Silurian and Lower Triassic foreland basins before the Cretaceous were rapid and occurred during the prototype development period, until the slow uplift and denudation during the early Cretaceous period at the end of Jurassic, which resulted in a slight decrease in the burial depth of stratum. In short, after the Indosinian Movement stopped the marine sedimentary development, a single subsidence-uplift cycle was established macroscopically, with the burial depth reaching its lowest in the early Yanshanian period and continuing to uplift till now.

The Middle and Late Silurian periods witnessed the beginning of the early oil generation stage of the mud shales in the Longmaxi Formation after developing Early Paleozoic shallow buried types, Late Paleozoic continuous balance types, and the Mesozoic deepburied types in the Jingmen exploration area. The oil generation reached peak stage in the Early Permian and reached mature and dry gas stages in the Middle and Late Triassic periods. The oil generation phase ended by the beginning of high burial depth during early Yanshanian. The hydrocarbon generation model controlled by the "drop early and lift late" burial history generally generated hydrocarbon continuously. The hydrocarbon generation process is considered single and continuous, although there are multiple phases. The major subsidence activities have not occurred after the late uplift. 


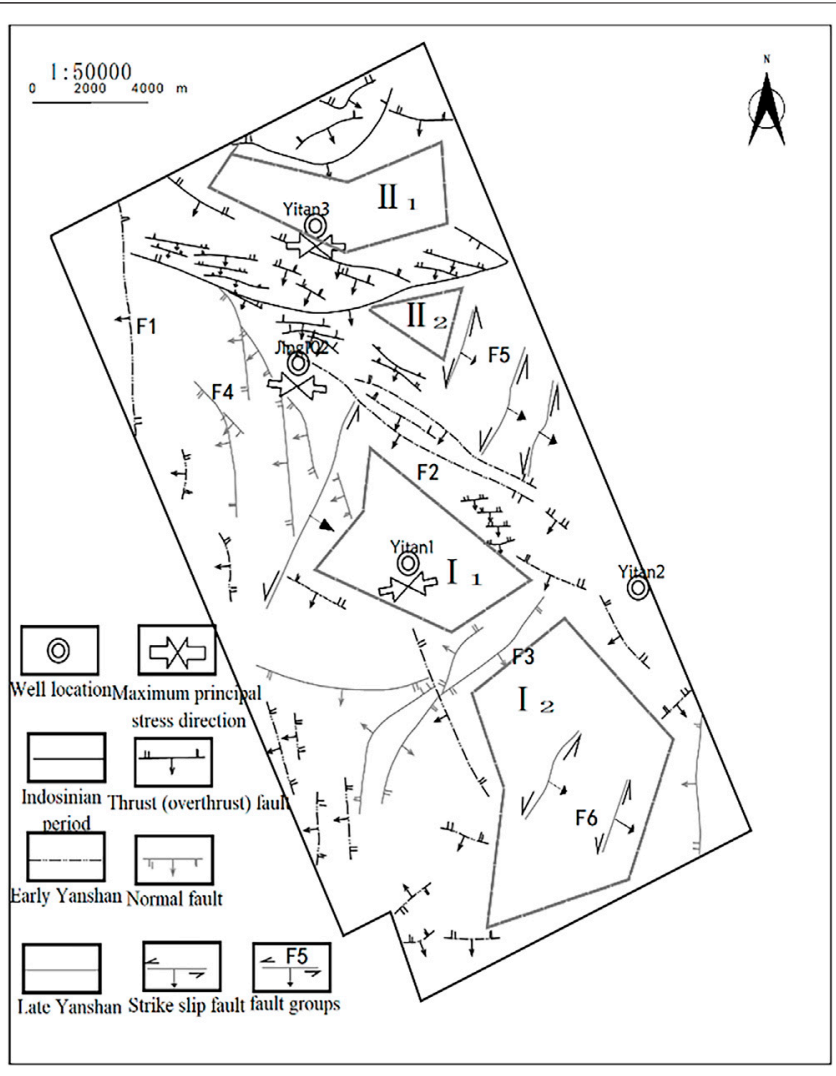

FIGURE 3 | The characteristics of the fracture structure and the map of the favorable area selection.

\subsection{Stages and Scale of the Development of Fracture Structures}

The Middle Yangtze area is characterized by complex fracture structures which have experienced long-term, multi-cycle evolution processes. The study area is located at the convergence of multiple fracture systems, with different stages and varying types of development of fault systems. This diversity in the stages and scales of fractures in the area has varying implications on the degree of shale gas preservation. After the significant hydrocarbon generation period, caused by the tectonic movements induced the uplift of stratum and development of large open fractures, which subsequently affected the shale gas reservoirs adversely to escape the shale gas. The shale strata and its roof and floor were damaged to varying extend by these fractures. Large-scale fractures generally cut vertically upwards further into the shale strata along with the rock layers in roofs and floors, extending farther laterally to provide an excellent channel through which the shale gas can escape. However, when the small micro-fractures are not extending to the roof and floor of the shale strata, gases will be preserved instead of escaping through the channel, and increases the space for gas storage will be increased, which catalyzes the shale gas production by enhancing the seepage flow of gas adsorption and desorption.

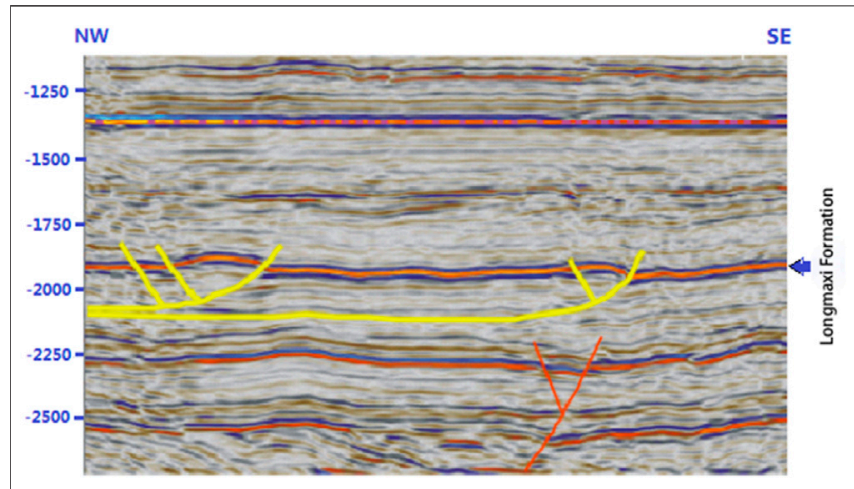

FIGURE 4 | Stratum and style of Indosinian tectonic development.

The major tectonic activities occurred in the Jingmen block through three tectonic phases, viz. the Indosinian, the early Yanshanian, and the late Yanshanian resulting in the threestage development of fracture structures are as shown in Figure 3.

\section{1) Indosinian tectonic phase.}

When the North China plate collided with the Yangtze plate, the Qin-Kun fracture system erupted vigorously and evolved an NWW-SEE thrust nappe structure in the north and associated folds in the study area in response to a compression toward the SN-SSW direction. The arcuate plane and the shingled/backpunched cross-section are shown in Figures 3, 4. The Indosinian period is dominated by tectonic activity in the Cambrian SystemEarly Silurian, with minor faults and few penetrating horizons. The detachment surface on the Caledonian Synsedimentary fault was over thrusted, resulting in the weakening of the tectonic activities toward the south.

The current tectonic activities are followed by the major hydrocarbon generation period of early Yanshanian and are characterized by low-amplitude overthrust and dispersion of fault gouges, with few penetrating stratums and relatively mild fault activity. The sealing capacity of fault structures enable the shale gas to get entrapped within the strata.

\section{2) Early Yanshanian tectonic phases}

The early Yanshanian period witnessed intense orogenic activities of the northern Qinling orogenic belt. The south and north orogenic belts underwent strong compression in the NESW direction causing the thrust and compression of the Middle Yangtze, which resulted in the formation of two arc-shaped structural systems in the south and north, and the development of NW-SE reverse faults as well as associated folds. However, Huangling paleo-uplift was withstood in the west, and the western tectonic shape was shifted from northwest to nearly south-north (Figure 3). The vertical depth of fault is relatively higher than the Indosinian reverse fault. Due to a more significant extent, the faults penetrate multiple horizons, and many have been penetrating the entire stratum, as in the case of F1, a north-south reverse fault in the northwest of 

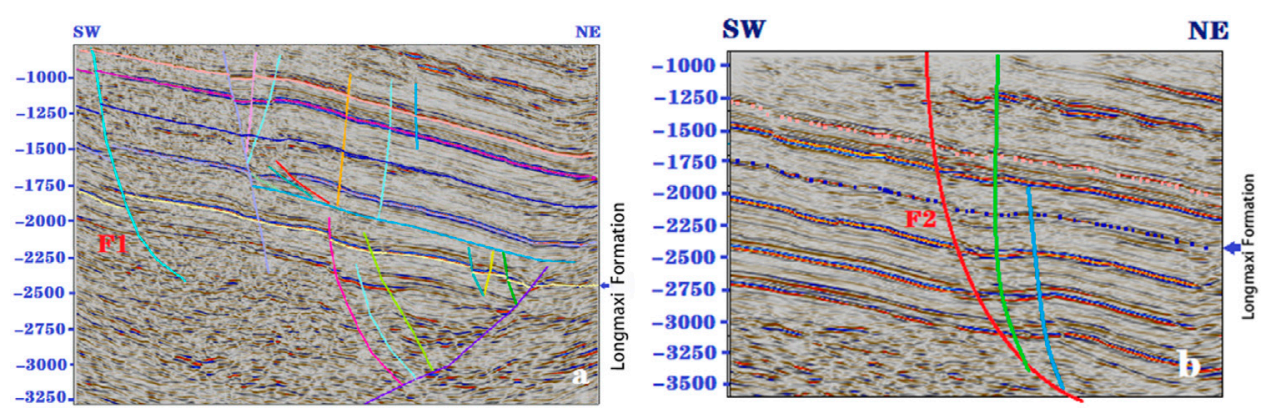

FIGURE 5 | Early Yanshanian structural reverse fault (Corresponding to the plane F1 reverse fault and F2 reverse fault formation).
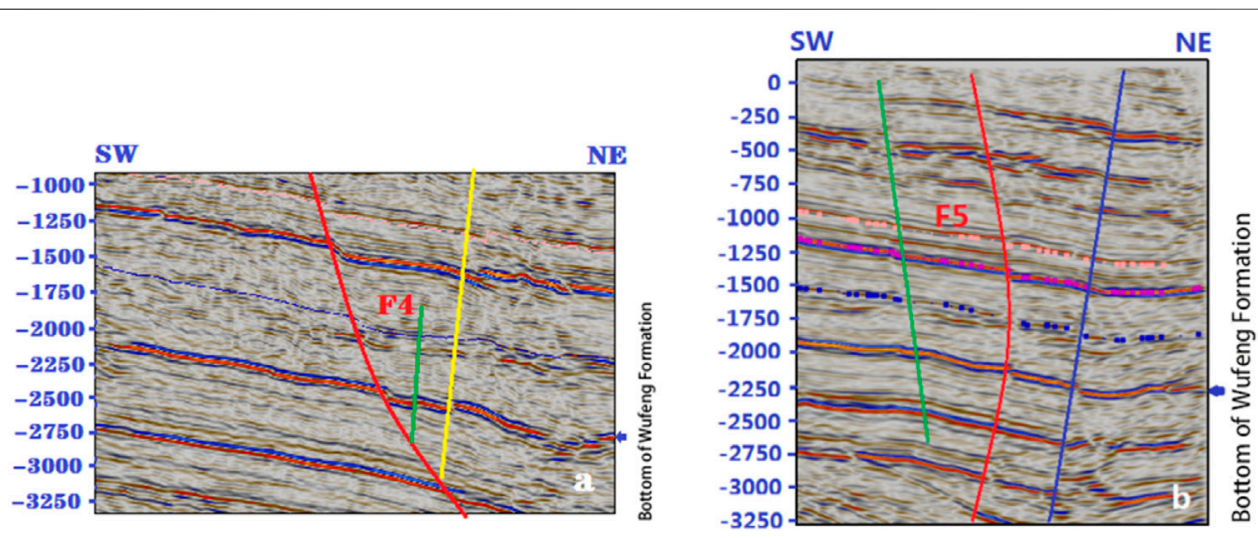

FIGURE 6 | Fault profile characteristics in late Yanshanian [(A) Midwestern herringbone fault; (B) Left-hand strike-slip structure in central-eastern]

the study area (Figure 5A). Similarly, the F2 reverse thrust fault formed (Figure 5B) in the direction of Jing 102-Yitan 2 inclines toward the northeast with steeper section occurrence at the top and slower at the bottom. The fault is fractured to the basement and formed a thrust anticline structure on the hanging wall, with a declining strength from north to south. It is a pressure cum sealing fault that fractured after the significant hydrocarbon generation period. The late Yanshanian extension did not cause the inversion of the fault, although the formed shale gas reservoir was damaged to a certain extent, as long as the well location placement is far away from the fault zone.

\section{3) Late Yanshanian tectonic episode.}

The late Yanshanian witnessed multiple groups of fractures due to $\mathrm{E}-\mathrm{W}$ stretching, which include the $\mathrm{S}-\mathrm{N}$ trending normal fault on the west side of Well Jing 102, the NE left-lateral strikeslip fault on the east side of Well Jing 102, and the E-W and NESW right lateral syncline en-echelon normal faults in the south as shown in Figure 3. The faults are generally gentle downwards and steep upwards, with several penetrating horizons, while the central NW-trending reverse fault was inverted into a normal fault. These faults are congruent with the active period and occurrence of the regional fault system.
1) Herringbone normal faults: These are plane-shaped faults located in the mid-west of the block, toward the western side of Well Jing 102, along the NNW-near NS direction. The main fault extends farther, turning from NNW to near NS direction, while the secondary faults have limited extension, with NNW orientation (Figure $2 \mathrm{~F} 4$ fault group). The profile is characterized by sharp uphill and mild descending, with a reverse $\mathrm{Y}$-shaped combination of secondary faults and major faults (Figure 6A).

2) Parallel strike-slip structures: These structures are concentrated in the east of Jing 102, well toward the central and eastern parts of the study area. Several NNE nearly parallel left-lateral strike-slip faults occur over the plane of these structures (Figure 2 F5 fault group).

The development of these structures ended at the reverse fault development zone in the early Yanshanian trending NW direction (Figure 2 F2 fault zone). The section is virtually vertical, with several parallel fault planes, mostly running from the surface to the basement in the longitudinal direction (Figure 6B).

3) Syncline en-echelon faults combination: These faults were developed in the central and southern part of the study area, with the first and final sections of several faults overlaid and 


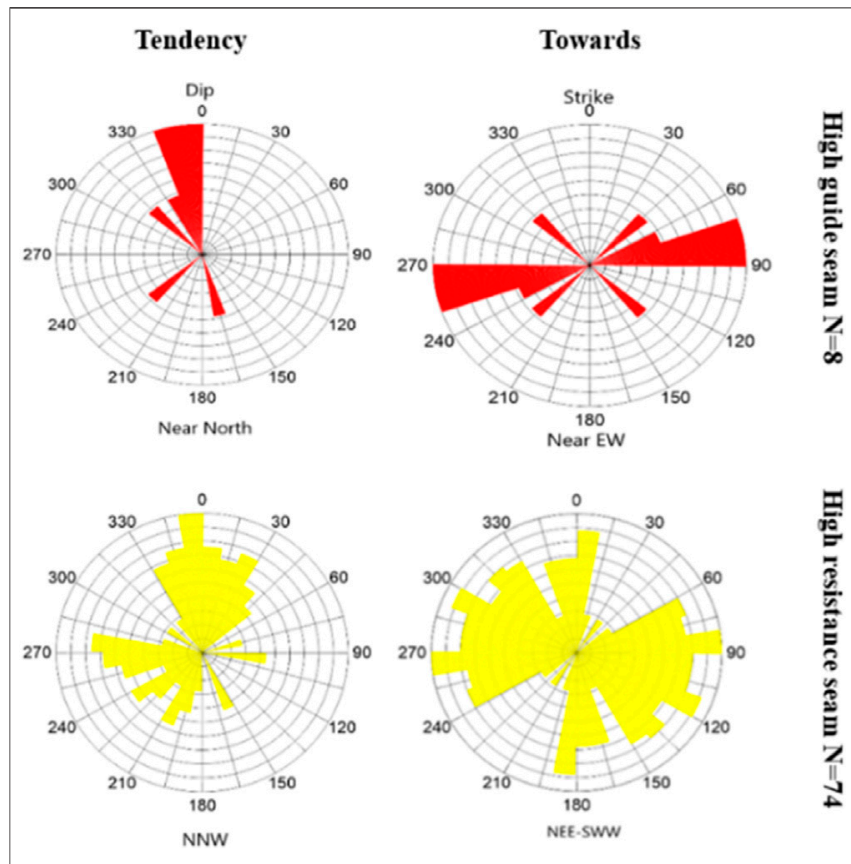

FIGURE 7 | Log interpretation of natural fracture development characteristics in yitan 3 well.

linked (Figure 2 F6). The descent gradient is mild, while the ascending profile is severe. The normal faults or growth faults below the Linxiang Formation are apparent, whereas the occurrence planes above the Linxiang Formation are steep and practically vertical.

In the late Yanshan period, most faults were open with gentle downhill and steep uphills with several penetrating layers. Most of them are faults that occurred after the significant hydrocarbon generation period, which is not conducive to shale gas preservation. Hence, The late Yanshan normal faults and strike-slip fault zones should be far from the well placement deployment.

\subsection{Development Characteristics of Structural Fractures and Their Influence on Shale Gas Preservation}

Large-scale faults of various stages control the tectonic pattern of the study area. In particular, penetration of the roof and floor of the shale strata exposed the fault of the Wufeng FormationLongmaxi Formation shale reservoir, influencing the scale of subsequent fracture growth. A high number of tiny secondary faults and minor fractures will follow the development in the adjacent strata during the thrust nappe and stress of the major faults in the research region. The primary fractures of the reservoir have an important influence on the preservation of shale gas and the initiation and extension of hydraulic fractures (Wang et al., 2018). This paper examines the fracture development types, angles, connectivity, and other factors using core observations and FMI imaging logging results to study the characteristics of fracture development in different regions and their influence on shale gas preservation.

The analysis of fracture phases is mainly focused on FMI interpretation of fracture strike and dip angle occurrence in four single shale gas Wells (Jing 102, Yitan 1, Yitan 2 and Yitan 3) in the Wufeng Formation-Longmaxi Formation. The formation period of fractures is evaluated from the perspective of structural deformation characteristics, including the structural pattern, structural stress, and structural movement experienced in the study area, and the restriction and cutting relationship between fractures.

Tectonic fractures in the study area are mainly divided into three phases: Indosinian, Early Yanshan period, and Late. During the Indosinian period, nearly EW, NW, and NE conjugate fractures were developed under the control of the maximum principal stress in the NNW-SSE direction. In the early period of Yanshan, a network of natural fractures with a dominant NW trend were formed along the direction of the Jing 102-Yitan 2 rift zone due to the strong compression in the NE-SW direction. The late Yanshanian was developed near EW trending due to the influence of near EW trending tension, with high-angle fractures along NW and NE direction, penetrating the Indosinian and early Yanshanian fractures (Figure 7).

The high-angle fractures mainly were formed along the late Yanshanian stretch due to the strike-slip effect according to the tectonic activity period formed by natural fractures. The intense compression of the Indosinian-early Yanshanian period resulted in the low-angle detachment fracture and structural deformation.

1) The characteristics of fracture development in the Indosinian period.

The NWW-SEE thrust nappe structure and associated folds were formed in the study area in response to the Indosinian thrust nappe. The development of minor faults and natural fractures, and interlayer sliding structures are evident from the reservoir core (Well Yitan 3) (Figure 8A). The core has 74 high resistance fractures (filled with high-resistance minerals) and eight high conduction fractures. The direction of the high-guide seam and high-resistance seam is the same and is near the east-west. Fractures are mainly distributed in the Long 2 Member and second sub-member of Long 1 . The L114-WF reservoir has developed vertical fractures (Figure 8B).

From the perspective of fracture development characteristics, micro-fractures and fractures can increase the storage space of shale gas. On the one hand, because they do not cut through the top and bottom strata, they cannot be used as a passage for shale gas escape which is conducive to shale gas preservation.

In addition, horizontal bedding layers (interlayer fractures) were developed at the bottom of Wufeng and Longmaxi Formations in Well Yitan 3. The weakening of upward development might have a significant impact on permeability anisotropy and artificial fracturing seam net form.

\section{2) Feature of early crack development in Yanshan.}

In the central-southern NW-SE and western near S-N trends, the studied region is significantly compressed in the NE-SW 


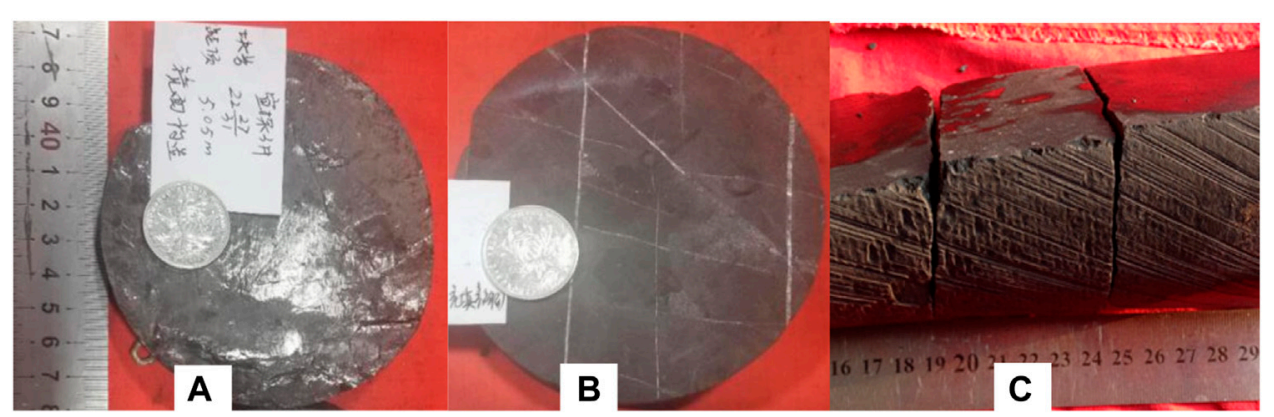

FIGURE 8 | Characteristics of structural fractures in Indosinian period (A,B) and early Yanshanian period (C). (A) Mirror structure (L114); (B) conjugate shear joints (L112); (C) High angle natural fractures (L112, see mirror structure).

TABLE 1 | The Angle between the fault strike and the direction of the maximum horizontal principal stress in Jingmen block.

Fracture

period and type
Number

of larger fractures
Main trend of the

fractures
The number of

fractures where the

angle between the

direction of the

maximum horizontal principa

stress and the

direction of the

fracture is greater

than $45^{\circ}$

Reverse fault in the Indosinian tectonic period

Early Yanshanian reverse fault

Late Yanshanian normal fault

Late Yanshanian strike-slip fault
Near east-west-Northwest west

North-west, North-south

Near North-South, Near East-West

Northeast
2

15

10

6

TABLE 2 | Summary of average index parameters of organic shale reservoirs in shale gas wells of the Jingmen Block.

\begin{tabular}{|c|c|c|c|c|}
\hline Hashtag & Yitan 3 & Jing 102 & Yitan 1 & Yitan 2 \\
\hline \multicolumn{5}{|l|}{ Reservoir parameters } \\
\hline High-quality shale section (L113-WF) thickness/m & 19.5 & 20.0 & 18.0 & 21.0 \\
\hline Natural gamma mean/API & 160.0 & 173.0 & 171.5 & 180.9 \\
\hline TOC content $/ \%$ & 1.0-5.9/average2.8 & 1.4-4.9/average3.2 & 1.2-4.6/average3.3 & 1.0-4.7/average3.3 \\
\hline Effective porosity/\% & 1.3-6.1/average3.8 & 1.4-4.9/average3.5 & 1.2-4.8/average3.6 & 1.1-6.2/average3.6 \\
\hline Total air content $/ \mathrm{m}^{3} \mathrm{t}^{-1}$ & $1.3-6.5$ /average4.0 & 1.3-6.5/average3.6 & 1.3-5.1/average3.8 & 1.4-7.1/average 4.0 \\
\hline Formation pressure coefficient & 1.48 & 1.25 & 1.34 & 1.43 \\
\hline Test production/104 m³/d & - & - & $4-5$ & - \\
\hline
\end{tabular}

direction, forming reversal faults and related folds. High-angle fractures (dip angle of roughly $80^{\circ}$ ) were formed in the core of Well Jing 102, which exhibited mirror structures (Figure 8C). L111L114 has nearly vertical and WF group cracks, wherein the former are not filled, and the latter is filled with calcite by the strong compression and shearing effect of the early Yanshanian. The FMI imaging interpretation shows that fractures in Well Jing 102 are mostly northeast-trending high-guiding fractures, tending to NW, and mostly high-guiding fractures of unfilled material.

The tiny beds of L114L113 in Well Yitan 2 have formed highangle shear fractures with virtually vertical fractures in the first-line rift zone of Well Jing 102-Yitan 2, and the fracture surface is straight and smooth with no infill. It is formed by brittle shear fracture of mud shale under local or regional tectonic stress, which enhances the seepage and accumulation capacity of shale gas. If it is connected to the significant faults of opening, shale gas may escape.

The early Yanshan fractures, dominated by unfilled highconductivity fractures, are located near the rift zone, developed after the peak period of hydrocarbon generation, and may be connected to surface penetrating faults (such as the F2 fault group), which is not conducive to the preservation of shale gas. Therefore, the formation pressure coefficient of Well Jing 102 with the development of reservoir fractures is lower than other wells in the block (1.25), and the gas content is relatively low, $3.6 \mathrm{~m}^{3} / \mathrm{t}$ (Table 2). It demonstrates that natural cracks and faults may reduce the efficacy of caprock to some extent. 

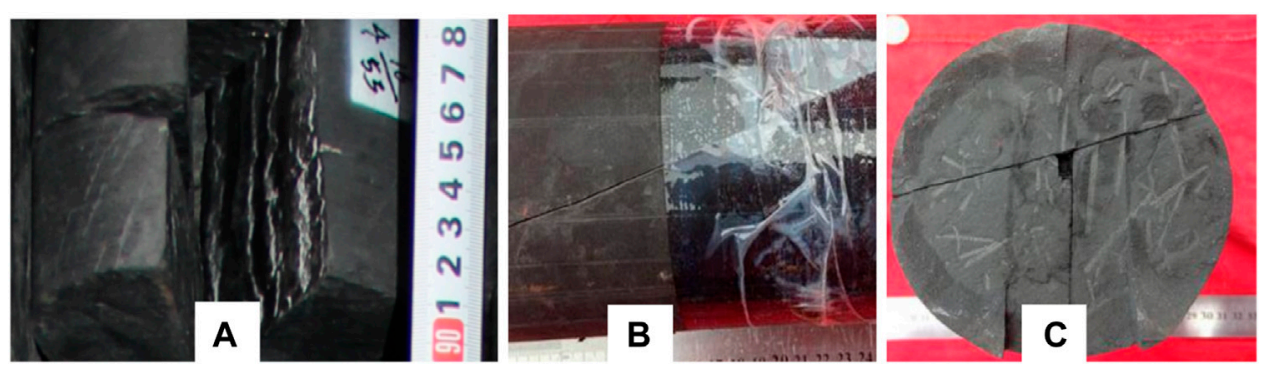

FIGURE 9| Characteristics of structural fractures in late Yanshanian period (Yitan2 well). (A) 3,971.6 m, black shale in the lower part of L114; (B) 3,495.61 m high angle fracture; (C) $3,495.28 \mathrm{~m}$, conjugate fracture.

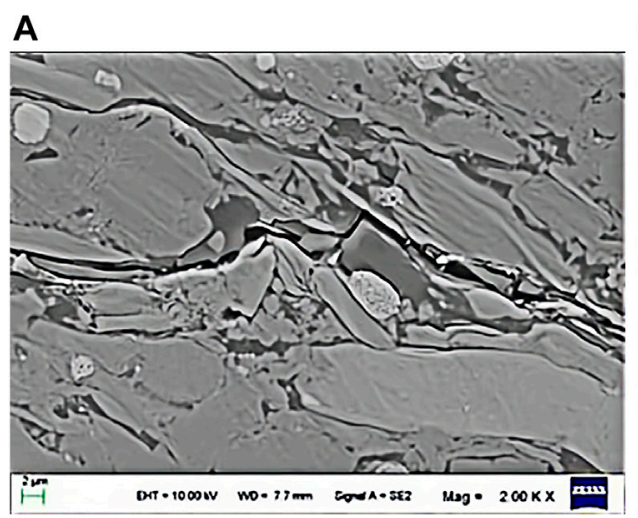

B

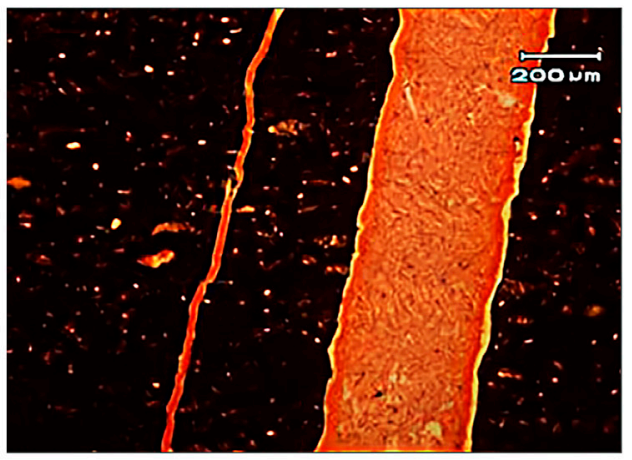

FIGURE 10 |Characteristics of microfractures in late Yanshanian period (Yitan 1 well). (A) 3,498 m, L111, fractures, mineral particles influence fracture morphology; (B) 3,495.7 m, L112, Cracks, calcite filling.

3) Fracture development characteristics in the late Yanshan period

The natural fractures formed by regional tensional tectonic stress are nearly vertical, extending to tens of centimeters. The fracture surface will be straight and smooth when the core is cracked along the fracture with no filling. The longitudinal fault step emerges in the cross-section, which has a mirror structure. For example, parallel strike-slip shear cracks in Well Yitan 2 (Figure 9A) may increase shale gas seepage and accumulation capacity. Therefore, if it is connected to significant open faults, shale gas may escape through it.

The FMI logging of Longmaxi Formation in Well Yitan 1 could explain 49 natural fractures, most characterized by high conductivity. The formation layers were primarily developed in the lower part of Long 2 Member. The center and upper sections of the second sub-member of the Long 1 Member and the top of the Wufeng Formation have both produced high conduction and high resistance cracks. The cored intervals of Well Yitan 1 show that natural fractures are mostly vertical fractures and highangled (Figure 9B). Conjugate fractures could be observed on the core section (Figure 9C). Some of the fractures were filled with quartz and calcite.

Figure 10 shows micro-fractures in the high-quality shale member of Well Yitan 1. The extension of smaller microstructures is affected by the shape and arrangement of mineral particles, while the larger micro-fractures are less affected by the mineral particles.

\subsection{The Influence of Modern Tectonic Stress Field on Shale Gas Preservation}

The magnitude and direction of the current maximum horizontal principal stress have a significant and direct impact on shale gas preservation. The sealability of the fault is determined by the angle between the directions of the maximum horizontal principal stress and fault/fracture, which are generally positively correlated (Chen et al., 2003). Previous studies show (Qi et al., 2017; Tian et al., 2017; An-jiang et al., 2018) that the sealability of the fault is roughly divided into two grades based on the angle between the direction of the maximum horizontal principal stress and the direction of the fault, and the categories are good and poor sealability. The fracture sealing performance is good when the angle between the maximum horizontal primary stress direction and the fracture direction is larger than $45^{\circ}$, and it is poor when the angle is less than $45^{\circ}$.

Based on the measured maximum horizontal principal stress direction in Jingmen area, well Yitan 3 is $90^{\circ}$, well Jing 102 is $95^{\circ}$, and well Yitan 1 is $80^{\circ}$. The actual measurement results show that despite the complex structural environment of the study area, the 
maximum horizontal principal stress directions of multiple drillings are consistent. In other words, the Himalaya orogeny during the Himalayan-Neotectonic active period caused the current maximum horizontal stress direction to be approximately east-west (about $90^{\circ}$ ), and the extension environment in the late Yanshanian was turned into the compression environment. The angles between the maximum horizontal principal stress and the faults of different structural stages and types differ significantly, which is evident from the angle between the fault strike and the direction of the maximum horizontal principal stress in the Jingmen area (Table 1; Figure 3). The angle between the low-angle Indosinian period reverse faults in the northeast of the block with the direction of the maximum horizontal principal stress approximately $90 \%$ less than $45^{\circ}$. However, the early Yanshanian period reverse faults distributed in the western edge of the block and the first-line rift zone of Jing 102-Yitan 2 well. The normal fault is distributed in the late Yanshanian toward the western side of jing 102 well, yitan 2 well first-line rift zone. Strike-slip faults with an angle higher than $45^{\circ}$ are found across the Middle East and south of the block, with the highest horizontal significant stress direction accounting for nearly $80 \%$. The Indosinian period reverse fault cannot form an effective plugging of shale gas due to the angle between the maximum horizontal principal stress direction of the current tectonic stress field and the fault strike, which is not favorable for the preservation of shale gas. However, the reverse faults in the early Yanshan and the normal, as well as strike-slip faults in the late Yanshan, are conducive to the preservation of shale gas.

\section{ANALYSIS AND DISCUSSION}

The buried depth of the bottom boundary of the Wufeng -Longmaxi Formations in the target layer of the study area declines progressively from less than $2,500 \mathrm{~m}$ in the west to nearly $4,500 \mathrm{~m}$ in the east. About $60 \%$ of the burial is occupied up to an approximate depth of 3,500-4,500 m. The overall structure is monoclinic, with high southwest and low northeast axis, softer strata, and minor variations. Back reverse thrust, echelon, parallel, inversion, rift, and other microstructures have developed in the local structure.

\subsection{The Control of Tectonic Action on Shale Gas Preservation}

The study is characterized by three significant stages of development of structures that affect the preservation conditions of shale gas. The placements and kinds of various phases of structure development have varying impacts on shale gas preservation conditions. The structure belonging to the Indosinian period was developed in the northeastern part of the study area, striking nearly east-west to the northwest, with angle overthrust and fault gouge smear, with less penetrating layers. The structure is more favorable to the preservation of shale gas since it happened before the primary hydrocarbon producing phase (early Yanshan period). In addition, well placement should be taken into account at a certain distance from the thrust fault zone. The early Yanshanian structure is primarily developed in the western margin of the study area with irregular distribution in the first line of Jing 102-Yitan 2 wells and the southern area. Close to the denudation area, north-south high-angle thrust faults, high dip angles, several through-through horizons are present due to the obstruction of The Huangling uplift.

Along with these, the shallow burial depth and low gas content in the western margin make it not feasible for drilling. The fault breaks down to the basement in the first-line part of Jing 102 well-Yitan 2 well, which is steep on the top and slow on the bottom. In addition, an inversion normal fault was developed owing to the stress of the late Yanshan Mountains, and the hanging wall developed a thrust anticline structure. The peak of the main hydrocarbon generation period was followed by an open fault with strong activity and a fault. It is simple to let shale gas escape and destroy the produced shale gas reservoir, which is not good for shale gas preservation. Drilling projects should not be carried out on this line. Many groups of faults were formed in the late Yanshanian period under the influence of the east-west stretching background, and most of them were steep on the top and slow on the bottom with many through-through horizons. A herringbone normal fault trending S-N was developed on the west side of Well Jing 102. The area is characterized by the thick and wide distribution of faults, making it unsuitable for well placement. The project should be deployed away from the northeast of the NE strike-slip fault, on the east side of Well Jing 102, which penetrates mainly from the surface to the basement in the longitudinal direction. The combination of central-southern echelon faults has a modest development density and is located relatively far from the hedging extrusion deformation. This location is most suitable for well placement due to the wide and gentle structure, the medium burial depth, and high gas content, which is better than in the north.

On the one hand, the natural fracture system of various stages in the research region is an ideal storage space for shale gas, which can effectively improve the free gas content of shale gas due to significant seepage ability as it is a dominant channel for shale gas migration. Early low-angle detachment fractures and later highangle shear fractures interconnected with other types of fractures generated a complex network of fractures to provide a foundation for later hydraulic fracturing, which is favorable for shale gas development and extraction. High-angle shear fractures and lowangle slippage fractures are generally semi-open fractures. If penetrating fractures or the major faults emerge in the overburden, the shale gas will escape from the natural fracture system in the shale reservoir through the channel. The L12-WF small formation meets minor faults or high-angle shear fractures during drilling-logging stages, and the gas measurement of the developing section is low, often less than $1 \%$.

In addition, the pressure coefficient of the shale strata with higher is slightly lower (1.3-1.5), and the fracture-fault connections may induce leakage risks. The distribution and influence of hydraulic fractures may be affected by the heterogeneity of the fracture development method, posing a danger to the shale gas production. 


\subsection{Optimal Selection of Favorable Areas Based on Structural Control}

Multiple tectonic movements influenced the study region resulting in variations in the structural parameters of different blocks, including the stage, type, activity and openness, penetrating horizons, and development characteristics of structural fractures, etc., which affected the shale gas preservation in the area. The study area is roughly divided into two favorable areas (I1, I2) and two more favorable areas (II1, II2) with faults of different periods and different properties as boundaries (Table 2). Figure 2 illustrates characteristics of each favorable zone and are as follows:

$I_{1}$ : The tectonic activities of $I_{1}$ are relatively weaker with the gentle stratigraphic occurrence of fault structure in the early and late Yanshanian period, evidenced by small folds, medium to deep burial depth, high formation pressure coefficient, and high gas content.

12: The development density of the syncline en-echelon fault combination in late Yanshan was comparably lower. The distance from the hedge squeeze is relatively far from the north with weaker structural transformation strength, wide and gentle fold structure, medium burial depth, high formation pressure coefficient, high gas content, and hence this zone is suitable for deploying wells.

II1: This zone is characterized by penetrating horizons and is affected by the Indosinian thrust nappe structure. Natural fracture zones are well developed in this zone and are distributed in the Long 2 member and the second submember of Long1 member. Vertical fractures, mainly highresistance fractures, are developed in the L114-WF reservoir section. The tectonic facies is relatively minor in terms of shale gas leakage, with the occurrence of substantial leakage in multiple well sections of Longmaxi Formation in yitan-3 guide well, accounting for a total leakage of over 3,800 cubic meters. The development of minor faults or natural fracture zones caused well leakage, which adversely affected the sealability of the caprock. II2: This zone is characterized by the longitudinal penetration of faults from the surface to the basement with moderate development of fold structures. The area is also notable for the combined influence of the Indosinian thrust nappe structure, the early Yanshan compression structure, and a sinistral strike-slip fault in the late Yanshan period. The L112-WF section was dominated by the near-upright high conductive fractures with a northeast strike during the early Yanshan period. High conductivity fractures were developed in the lower part of Long 2 Member. High conductivity fractures and high resistance fractures developed in the middle and upper part of the second sub-member of Long 1 member and the top of Wufeng Formation in the late Yanshan Period. In each phase, the tectonic area far from the cut-through target layer is favorable for shale gas preservation.

\section{CONCLUSION}

1) The Jingmen block in central Hubei has a monoclinic structure with high southwest and low northeast axis, as well as a gentle stratum and minor variations. The local structure is complex and is characterized by the development of back-thrust, echelon, parallel, inversion, rift, and other structures.

2) The shale strata of Wufeng and Longmaxi Formations of upper Ordovician and Lower Silurian periods were undergone modification after their deposition through the three-stage tectonic processes viz., Indosinian, Early Yanshanian, and Late Yanshanian. Compression deformation was dominant in the Indosinian and early Yanshanian periods, while tensile and strike-slip were dominant in the late Yanshanian period.

3) Fractures of different structural stages and structural scales have different effects on shale gas preservation in the study area. A low-amplitude thrust nappe structure with a bow-shaped plane was formed during Indosinian period in the northeast along the NWW-SEE direction as a result of compression in the NS-SSW direction. The influencing horizon mainly belongs to the Cambrian-Early Silurian period, with minor faults, few penetrating horizons, and weakened tectonic activity toward the south. NW-SE reverse faults and associated folds were developed in the early Yanshan period in response to strong compression in the NE-SW direction. The tectonic traces in the west have changed from northwest to nearly north-south, and structures such as significant faults, steep dips, and multiple cutting layers were formed due to the resistance of the Huangling paleouplift in the west. The developing wells should be constructed in areas where the western margin is closer to the denudation zone, and the north-south thrust fault developed zones with shallow burial depth. The rift zones where the fault inversion in the first line of Jing 102-Yitan 2 well is in the late stage are unsuitable for well deployment and should not be considered for wee construction. In the late Yanshan period, multiple groups of faults were formed in response to the near E-W tensile background, which includes S-N trending normal fault on the west side of Jing 102 Well, NE left-lateral strike-slip fault on the east side of Jing 102 Well, and E-W and NESW right lateral syncline en echelon normal faults in the south. Most of these open faults were developed after a significant hydrocarbon generation period and penetrated several horizons with gentle downhills and steep uphills. Hence, this zone is not conducive to the preservation of shale gas.

4) During the thrust nappe and tension of the major faults in the study area, many secondary minor faults and fractures were developed in the nearby strata. The occurrence of target layer fractures, including interlayer low-angle slip fractures, conjugate shear fractures, mesh fractures, high-angle shear fractures, highangle strike-slip shear fractures, and high-angle fractures, and other types, were evidenced by core observation and FMI imaging logging results. The varying location and type of fracture development in different stages have a substantial influence on the preservation and migration of shale gas.

5) Based on the influence of structure on the preservation of shale gas, the study area is categorized into two favorable and two more favorable areas. 
6) As shale gas exploration has been initiated recently, the data on abundant shale gas pressure, gas content, gas composition, and related information is limited. Hence, the influence of structure on shale gas preservation can only be analyzed qualitatively. However, the analysis can be strengthened by considering the roof, floor, and hydrological conditions, which enable the accurate optimization of favorable areas based on structural control are minimal. Further, the development of exploration can also yield more experimental data, which can strengthen the conclusion.

\section{DATA AVAILABILITY STATEMENT}

The raw data supporting the conclusion of this article will be made available by the authors, without undue reservation.

\section{REFERENCES}

An, L., Hanyong, B., and Hai, L. (2016). Analysis of the Shale Gas Geological Conditions of the Upper Ordovician Wufeng Formation-Lower Silurian Longmaxi Formation in Hubei Province and Predict the Favorable Zone. Geology. Mineral Resour. South China 32 (2), 126-134.

An-jiang, S., Xiao-dong, F., You, Z., Xing-ping, Z., Wei, L., Guan-ming, S., et al. (2018). A Study of Source Rocks \& Carbonate Reservoirs and its Implication on Exploration Playsfrom Sinian to Lower Paleozoic in the East of Tarim Basin, Northwest China. Nat. Gas Geosci. 29 (1), 1-16. doi:10.11764/j.issn.16721926.2017.08.019

Bo, S., Bin, D., and Shugen, L. (2018). Discussion on Correlation between MultiStage Superimposed Tectonic Deformation and Shale Gas Preservation Condition in the Jiaoshiba Shale-Gas Fiedl, Sichuan,China. J. Chengdu Univ. Technology(Science Technol. Edition) 45 (1), 109-120.

Chen, Y., Zhou, X., and Yu, X. (2003). Sealing Factors of Faults and Their Sealing Effectsi. Pet. Exploration Develop. 30 (6), 38-40.

Chen, Z., Zhou, S., and Mei, J. (2016). Geological Evaluation of Upper OrdovicianLower Silurian Gas-Bearing Shales and Optional Potential Areas in the North of Dangyang Syncinorium Hubei. Mar. Pet. Geology. 21 (2), 22-28.

Deng, M., and He, D. (2018). The Geological Struture in the Dangyang Area and its Significance to the Shale Gas Exploration in Yichang Area,China. J. Chengdu Univ. Technology(Science Technol. Edition) 45 (4), 487-500.

Guo, T. (2016). Key Geological Issues and Main Controls on Accumulation and Enrichment of Chinese Shale Gas. Pet. Exploration Develop. 43 (3), 317-326. doi:10.1016/s1876-3804(16)30042-8

Guo, W., Tang, J., and Ouyang, J. (2021). Characteristics of Structural Deformation in the Southern Sichuan Basin and its Relationship with the Storage Condition of Shale Gas. Nat. Gas Industry 41 (5), 11-19.

Kongquan, C., Douzhong, Z., and Xiusong, T. (2020). Relationship between Geological Structure and Arine Shale Gas Preservation Conditions in the Western Middle Yangtze Block. Nat. Gas Industry 40 (4), 9-19.

Ma, Y. (2015). "Characteristics of Shale Reservoir and Controlling Factors of GasBearing for Longmaxi Formation," in Jingmen Area [D] (Chengdu, China: Southwest Petroleum University).

Qi, R., Yong, C., and Qing, Q. (2017). Preservation Conditions of Shale Gas in Longmaxi Formation of Dingshan Area. Pet. Geology. Eng. 31 (4), 22-25.

Shasha, S., Yun, R., and Dazhong, D. (2018). Paleogeographic Evolution of the Late Ordovician-Early Siurian in Upper and Middle Yangtze Regions and Depositional Model of Shale. Oil Gas Geology. 39 (6), 1087-1106.

Tian, R., Xianfeng, T., and Hao, C. (2017). Geological Features of Shale Gas Accumulation in the Lower Silurian Longmaxi Formation,Southeast Chongqing. Pet. Geology. Recovery Efficiency 24 (5), 17-26.

\section{AUTHOR CONTRIBUTIONS}

XL: Design the paper framework, propose constructive revisions, and be responsible for the final review of the paper. YW: Responsible for collecting and analyzing data, summarizing and sorting out data, drawing some maps, and writing the full text.

\section{ACKNOWLEDGMENTS}

Financial support for this work, provided by National Science and Technology Major Project (No. 2017ZX05035), the Fundamental Research Funds for the Central Universities No. 3142014025, and Key project of PetroChina Co. Ltd. (Nos 2017B49; 2019F-31) are gratefully acknowledged.

Wang, Z., He, P., and Guo, Z. (2018). Calculation of Initiation Pressure of Vertical Well for Coalbed Methane Considering Crack Characteristic index. Rock Soil Mech. 39 (S1), 369-377.

Xiao-Hong, C., Bao-ming, Z., Lin, C., Guo-Tao, Z., Pei-jun, L., and Miao, Z. (2018). Main Geological Controlling Factors and Enrichment Pattern of Shale Gas Reservoirs in the Late Ordovician-Early Silurian Strata of Yichang, Western Hubei Province. Acta Geoscientica Sinica 39 (3), 257-268. doi:10.3975/ cagsb.2018.050901

Xiaoxi, M., Zhihui, H., and Lei, W. (2018). History and Currentsituation of Shale Gas Exploration and Development. Xinjiang Pet. Geology. 39 (3), 372-376.

Xusheng, G. (2014). Rules of Two-Factor Enrichment for marine Shale Gas in Southern China: Understanding from the Longmaxi Formation Shale Gas in Sichuan Basin and its Surrounding Area. Acta Geologica Sinica 88 (7), 1209-1218.

Yuming, C., Xingxing, G., and Xiancai, S. (2013). Tectonic Evolution Characteristics and Mechanism in Western Hunan Hubei. Oil Geophys. Prospecting 48 (S1), 157-162.

Zhai, G., Bao, S., Wang, Y., Chen, K., Wang, S.-J., Zhou, Z., et al. (2017). Reservoir Accumulation Model at the Edge of Palaeohigh and Significant Discovery of Shale Gas in Yichang Area, Hubei Province. Acta Geoscientica Sinica 38 (4), 441-447. doi:10.3975/cagsb.2017.04.01

Zhihong, W. (2015). Late Fugitive Emission of Shale Gas from Wufeng-Longmaxi Formation in Sichuan Basin and its Periphery. Oil Gas Geology. 36 (4), 659-665. doi:10.11743/ogg20150416

Zou, C., Dong, D., Wang, Y., Li, X., Huang, J., Wang, S., et al. (2015). Shale Gas in China: Characteristics, Challenges and Prospects (I). Pet. Exploration Develop. 42 (6), 689-701. doi:10.1016/s1876-3804(15)30072-0

Conflict of Interest: The authors declare that the research was conducted in the absence of any commercial or financial relationships that could be construed as a potential conflict of interest.

Publisher's Note: All claims expressed in this article are solely those of the authors and do not necessarily represent those of their affiliated organizations, or those of the publisher, the editors and the reviewers. Any product that may be evaluated in this article, or claim that may be made by its manufacturer, is not guaranteed or endorsed by the publisher.

Copyright (C) 2022 Li, Wang, Lin, Ma, Liu and Zhang. This is an open-access article distributed under the terms of the Creative Commons Attribution License (CC BY). The use, distribution or reproduction in other forums is permitted, provided the original author(s) and the copyright owner(s) are credited and that the original publication in this journal is cited, in accordance with accepted academic practice. No use, distribution or reproduction is permitted which does not comply with these terms. 